\title{
Identification of corrosion on a hollow tube using vibration
}

\begin{abstract}
Vibration based technique have so far been focused on the identification of structural damage. However, not many studies have been conducted on the corrosion identification on pipes. The objective of this paper is to identify corrosion on pipes from vibration measurements. A hollow pipe, $500 \mathrm{~mm}$ in length with $63.5 \mathrm{~mm}$ in diameter was subjected to impact loading using an impact hammer to identify the natural frequency of the tube in two conditions i) without any corrosion and ii) with an induced localized $40 \mathrm{~mm}$ by $40 \mathrm{~mm}$ corrosion at the middle of the pipe. The shift of natural frequencies of the structures under free boundary conditions was examined for each node of excitation. The results showed that there is a shift in natural frequency of the pipe, between 3 and $4 \mathrm{~Hz}$ near to the corrosion area. It can suggested that that the impact vibration is capable of identifying of localized corrosion on a hollow tube.
\end{abstract}

Keyword: Corrosion; Free-free boundary condition; Impact testing; Pipe vibration 